\title{
LUMINOSITY OF A BLACK BODY AND TEMPERATURE
}

\author{
By Paul D. Foote and C. O. Fairchild
}

The relation between luminosity and temperature has been studied quite extensively by many investigators, especially $\mathrm{Dr}$. Ives and Dr. Nutting. Recently an interest has arisen in the subject from the standpoint of pyrometry. With the relation between luminosity and temperature established, a pyrometer may be devised for the measurement of temperature by means of observations upon the luminosity of a source, more especially a black body.

Two equations have been deduced representing this relation, one by Rasch and the other by Nutting. In the present paper these equations are derived by a new method, and a new equation also is obtained, which, however, is not essentially different from that derived by Nutting.

Luminosity is defined as the integral from $o$ to $\infty$ in respect to $d \lambda$ of the product visibility, $V$, and energy, $J$, of the radiating source thus

$$
L=\int^{\infty} V J d \lambda
$$

where

$$
\begin{aligned}
& V=f(\lambda) \\
& J=c_{1} \lambda^{-5} e^{-c_{2} / \lambda \theta}=\text { Wien's law. }
\end{aligned}
$$

The effective wave length, $\lambda_{\mathrm{L}}$, of the luminosity has been defined analytically by one of the writers ${ }^{1}$ in the following manner:

$$
\lambda_{\mathrm{L}}=\frac{\int_{0}^{\infty} V J d \lambda}{\int_{0}^{\infty} \frac{V J}{\lambda} d \lambda}
$$

The physical significance of this so-called effective wave length as far as optical pyrometry is concerned has been discussed else-

\footnotetext{
${ }_{1}^{1}$ Foote, J., Wash. Acad. Sci., 5, p. 526; rgr5. Complete paper, this Bulletin, 12, p. 483 , 1916. See also Hyde, Cady, and Forsythe, Phys. Rev., 6, p. 70, 1915; Astrophys. J., 42, pp. 294-304; 1915.
} 
where. But regarding equation (2) for the time being as simply a numerical relationship, the following expression is true:

$$
\frac{d \log L}{d \theta}=\frac{c_{2}}{\theta^{2}} \cdot \frac{\int_{0}^{\infty} \frac{V J}{\lambda} d \lambda}{\int_{0}^{\infty} V J d \lambda}=\frac{c_{2}}{\theta^{2}} \frac{\mathrm{I}}{\lambda_{\mathrm{L}}}
$$

Suppose that equation (2) is of the form:

$$
\lambda_{\mathrm{L}}=a+b / \theta+c / \theta^{2}+\ldots .
$$

where $a, b, c$, etc., are dimensional constants.

Accordingly, if $\lambda_{\mathrm{L}}$ is expressed as a known function of $\theta$, this function may be substituted in (3), integrated, and $L=f(\theta)$ obtained.

The quantity $\lambda_{L}$ is the value of the $\lambda$ - coordinate of the center of gravity of the curve $\frac{J V}{\lambda}$ versus $\lambda$, not of the luminosity curve, as sometimes assumed. In the present work values of $\lambda_{\mathrm{L}}$ for temperatures ranging from 1000 to $7000^{\circ}$ absolute were obtained directly from the $\frac{J V}{\lambda}$ versus $\lambda$ curves by means of the Amsler Integrator No. I; the values of $J$ for various wave lengths were computed from Wien's law, using $c_{2}=\mathrm{I} 445 \mathrm{O}$ micron degrees, ${ }^{2}$ and the values of $V=f(\lambda)$ were obtained as a mean of data by Ives, ${ }^{3}$ Nutting, ${ }^{4}$ and Hyde and Forsythe. ${ }^{5}$ No experimental observations are included in the present paper, the primary object of which has been to point out a simple method of deriving the luminositytemperature relations and to consider their applicability to temperature measurement.

The possible forms of the luminosity equation are as follows:

Case I, $\lambda_{\mathrm{L}}=a$, i. e., the constants $b, c$, etc., of equation (4) are zero.

Substituting in (3) and integrating:

$$
\log L=-\frac{c_{2}}{\lambda_{\mathrm{L}}} \cdot \frac{\mathrm{I}}{\theta}+\text { const. }
$$

This is the well-known Rasch ${ }^{6}$ equation which has been recently applied by Langmuir ${ }^{7}$ for the determination of the melting point. of tungsten. The value of $\lambda_{\mathrm{L}}=a$ is known as the Crova wave length because Crova ${ }^{8}$ first pointed out that there exists a wave

2 Coblentz, this Bulletin, 10, pp. I-77; I9r4.

3 Ives, Phil. Mag., December; rgr2.

'Nutting, Phil. Mag., 29, p. 306; I9I5.

${ }^{5}$ Hyde and Forsythe, Phys. Rev., 6, p. 70; rgr 5.
6 Rasch, Anr. Phys., 14, p. I93; I904.

7 Langmuir, Phys. Rev. (2), 6, p. I38; 1915.

8 Crova, Compt. rend., 98, p. 512; 188 r. 
length in the spectral energy curves of two sources at which the ratio of the radiation intensities equals the ratio of their total luminosities. This wave length has generally been considered to be $\lambda_{\mathrm{L}}=a=0.58 \mu$. Ives ${ }^{9}$ and Pirani ${ }^{10}$ showed, however, that the value is not constant if the radiation from black bodies at various temperatures is compared, the wave length shifting slightly toward the green as the temperatures of the sources increase. Equation

(5) may be written as follows:

$$
L=A e^{-c_{2} / \lambda_{\mathrm{L}} \theta}
$$

Case II, $\lambda_{\mathrm{L}}=a+b / \theta$

Substituting in (3) and integrating:

$$
L=A\left(\frac{B}{\theta}+\mathrm{I}\right)^{-C} \text { where } B=\frac{b}{a} \text { and } C=\frac{c_{2}}{b} .
$$

This is the equation derived by Nutting ${ }^{11}$ by obtaining a mathematical expression for $V=f(\theta)$ and substituting in equation (I) and integrating.

Case III, $\lambda_{\mathrm{L}}=a+b / \theta+c / \theta^{2}$

whence from equation $(3)$

$$
\begin{aligned}
& L=A\left(\frac{B+\theta}{C+\theta}\right)^{D} \text { where } \\
& B=\frac{b-\sqrt{b^{2}-4 a c}}{2 a} \\
& C=\frac{b+\sqrt{b^{2}-4 a c}}{2 a} \\
& D=\frac{c_{2}}{\sqrt{b^{2}-4 a c}}
\end{aligned}
$$

Case III, and in general Case II, are sufficiently accurate for representing the luminosity of a black body at various temperatures from 1000 to $7000^{\circ}$ absolute. Table $\mathrm{I}$ and Fig. I show the variation of $\lambda_{\mathrm{L}}$ with $\theta$. For comparison, the values of the wave length corresponding to the centers of gravity of the luminosity curves are also shown. The difference between these wave lengths, $\lambda_{\text {cg }}$, and the true "effective" wave lengths is slight-about $0.003 \mu$.

${ }^{9}$ Ives, Phys. Rev., 32, p. 3 r6; rgrr. See also Ives and Kingsbury, Washington meeting of Ill. Eng. Soc.; I9I5.

${ }_{10}$ Pirani, Verh. d. Phys. Ges., p. 219; 1915.

11 Nutting, this Bulletin, 5, p. 306; x915. Also Phil. Mag., 29, p. 306; 1915. 


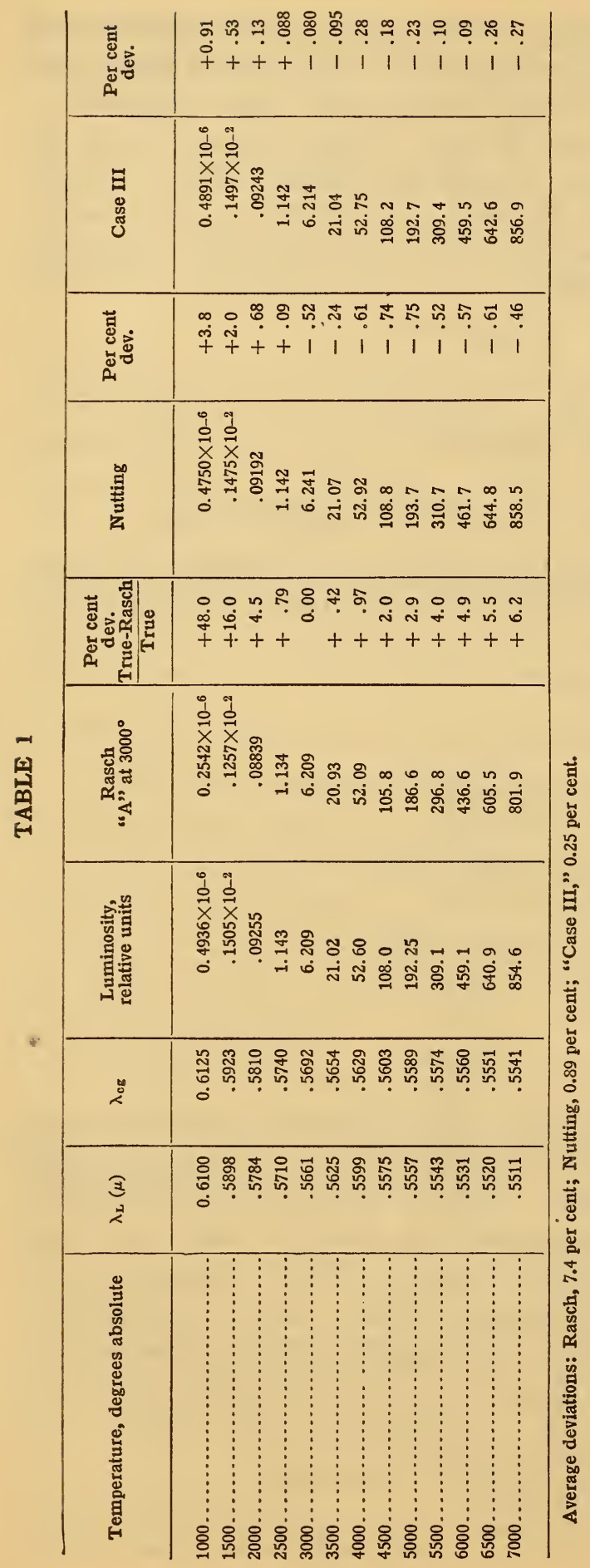


Using the data for $\lambda_{\mathrm{L}}$ in Table $\mathrm{I}$, the following are the luminosity equations:

Case I. $\quad \lambda_{\mathrm{L}}=a=$ mean of all values of $\lambda_{\mathrm{L}}=0.5663$

$$
L=30700 e^{\frac{-25517}{\theta}} \text { (relative units) }
$$

Case II. $\lambda_{\mathrm{L}}=.542 \mathrm{I}+\frac{69.732}{\theta}$ (least square solution)

$$
L=37400\left(\frac{\mathrm{I} 28.63}{\theta}+\mathrm{I}\right)^{-207.22} \text { (relative units) }
$$

Case III. $\lambda_{\mathrm{L}}=.539 \mathrm{I}_{5}+\frac{86.0 \mathrm{I} 7}{\theta}-\frac{\mathrm{I} 5 \mathrm{I} 60}{\theta^{2}}$ (least square solution)

$$
L=3779 \circ\left(\frac{\theta-105.92}{\theta+265.46}\right)^{72.1662} \text { (relative units) }
$$

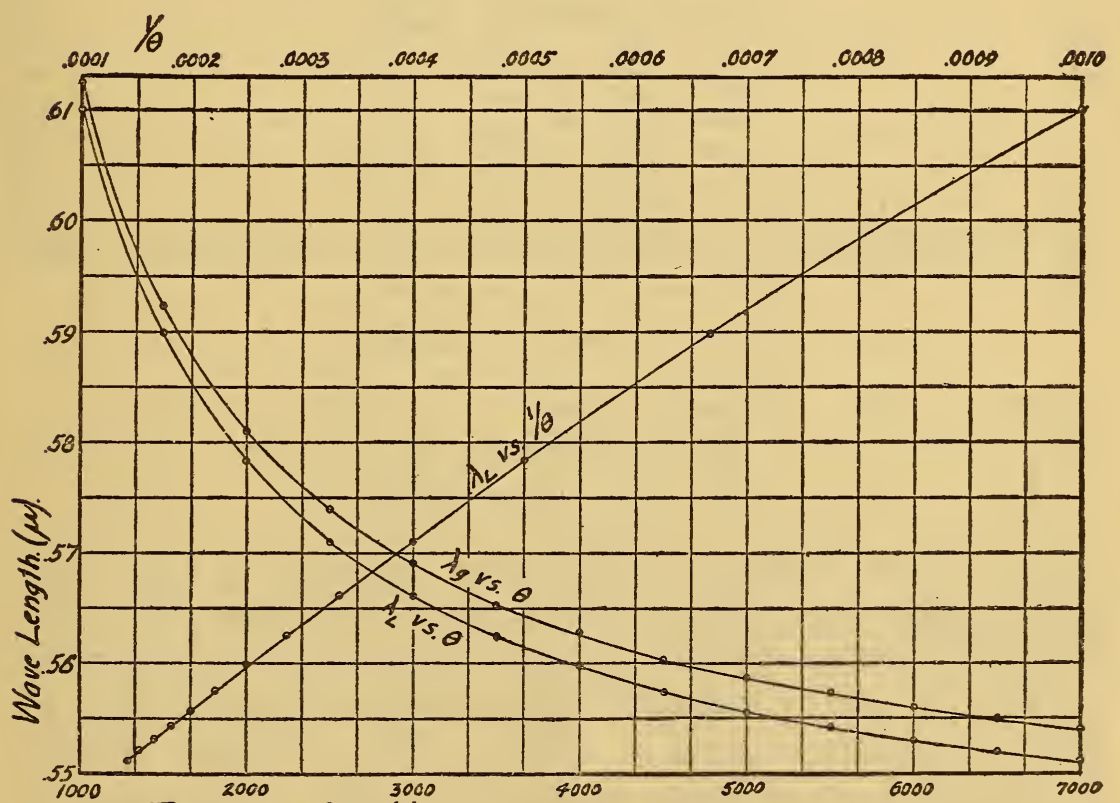

Temperoture ${ }^{\circ}$ Alas $(\theta)$.

FIG. I.-Effective wave length and "center of gravity" as a function of the temperature

Table I contains the computations of luminosities by these three equations. The equation represented by Case III fits the luminosity-temperature curve (computed on the basis of Ives', Nutting's, and Hyde and Forsythe's visibility data) with no deviations larger than the errors involved in the determination of $L$ by the planimeter. The Nutting equation holds almost as accurately, but the Rasch equation is entirely unsatisfactory. In the table the Rasch equation has been arbitrarily made to agree 
with the observed luminosity at $3000^{\circ}$ absolute, since the mean value of the Crova wave length from 1000 to $7000^{\circ}$ is the Crova wave length at this temperature. When thus adjusted the equation is in error by nearly 50 per cent at $1000^{\circ}$ absolute.

Application of the above equations to the measurement of temperature:

Either the Nutting formula or the equation represented by Case III is applicable to temperature measurement of a black body. The Rasch formula should not be used. As an example of the errors, expressed in temperature, which may be expected from the use of this latter equation, suppose the luminosity pyrometer were calibrated at $3000^{\circ}$ absolute:

\begin{tabular}{|c|c|c|}
\hline True $\theta$ & Observed $\theta$ & $\begin{array}{c}\text { Error, } \\
\text { degrees }\end{array}$ \\
\hline 1000 & 1027 & 27 \\
3000 & 3000 & 0 \\
7000 & 7125 & 125 \\
\hline
\end{tabular}

If the pyrometer were calibrated at about $1000^{\circ}$ absolute, then:

\begin{tabular}{|c|c|c|}
\hline True $\theta$ & Observed $\theta$ & $\begin{array}{c}\text { Error, } \\
\text { degrees }\end{array}$ \\
\hline 1000 & 1000 & 0 \\
3000 & 3227 & 227 \\
7000 & 9800 & 2800 \\
\hline
\end{tabular}

Data on the luminosity-temperature relation of a black body are so meager and unsatisfactory that as yet it does not appear advisable to assign absolute values to the constants $A$ in formulas 7 and 8. A cursory summary of experimental determinations by various observers is given in Table 2. Many of these data are old and based on incorrect temperature scales. Expressing the luminosity in candles $/ \mathrm{cm}^{2}$ they give a numerical value of $A$ in equation (8), Case III, as follows:

$$
A=2.0 \times 1 \mathrm{IO}^{7} .
$$


TABLE 2

\begin{tabular}{|c|c|c|c|}
\hline Temperature, degrees absolute & Candles $/ \mathrm{cm}^{2}$ & Authority & $\begin{array}{l}\text { A/107 } \\
\text { Case III }\end{array}$ \\
\hline $1449 .$. & 0.38 & Lummer and Pringsheim ......... & 1.70 \\
\hline $1597 \ldots \ldots \ldots \ldots \ldots \ldots \ldots \ldots \ldots \ldots \ldots \ldots \ldots \ldots \ldots$ & 2.0 & .....do........................... & 1.87 \\
\hline 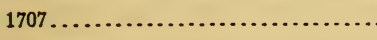 & 5.8 & 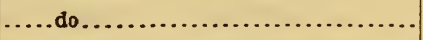 & 2.00 \\
\hline $2028 \ldots \ldots \ldots \ldots \ldots \ldots \ldots \ldots \ldots . . . \ldots \ldots \ldots$ & 82. & Nernst........................ & 2.82 \\
\hline 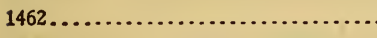 & 0.34 & .....do............................... & 1.31 \\
\hline 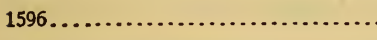 & 2.17 & ....do............................ & 2.05 \\
\hline 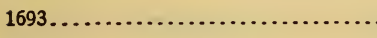 & 4.8 & ....do................................... & 1.87 \\
\hline $2623 . \ldots \ldots \ldots \ldots \ldots \ldots \ldots \ldots \ldots \ldots \ldots$ & 1089. & .....do.............................. & 2.24 \\
\hline $2027 \ldots \ldots \ldots \ldots \ldots \ldots \ldots \ldots \ldots \ldots \ldots \ldots \ldots \ldots$ & 59. & .....do do............................... & 2.04 \\
\hline $2182 \ldots \ldots \ldots \ldots \ldots \ldots \ldots \ldots \ldots \ldots \ldots \ldots \ldots \ldots$ & 162. & .....do................................. & 2.33 \\
\hline $2290 \ldots \ldots \ldots \ldots \ldots \ldots \ldots \ldots \ldots$ & 245. & .....do................................. & 2.05 \\
\hline 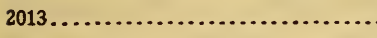 & 47. & 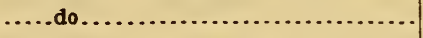 & 1.77 \\
\hline 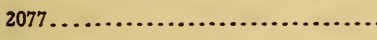 & 73. & ....do................................ & 1.88 \\
\hline 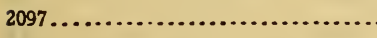 & 90. & .....do do.............................. & 2.06 \\
\hline 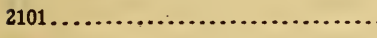 & 100. & 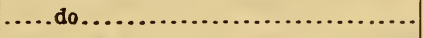 & 2.25 \\
\hline 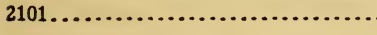 & 101. & 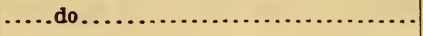 & 2.26 \\
\hline 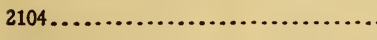 & 79. & ....do do............................. & 1.74 \\
\hline $2107 \ldots \ldots \ldots \ldots \ldots \ldots \ldots \ldots \ldots \ldots \ldots \ldots \ldots$ & 86. & .....do................................. & 1.86 \\
\hline $2245 \ldots \ldots \ldots \ldots \ldots \ldots \ldots \ldots$ & 202. & 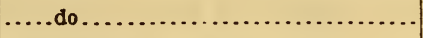 & 2.10 \\
\hline $2284 \ldots \ldots \ldots \ldots \ldots \ldots \ldots \ldots \ldots \ldots \ldots \ldots \ldots$ & 225. & .....do do............................... & 1.93 \\
\hline 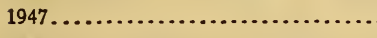 & 40. & 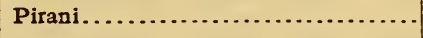 & 2.30 \\
\hline 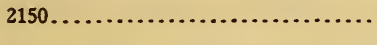 & 127. & 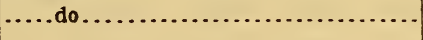 & 2. 17 \\
\hline Mean $\mathbf{A}=$ & & & $2.0 \times 10^{7}$ \\
\hline
\end{tabular}

Langmuir ${ }^{12}$ applied the Rasch equation, with constants determined by Nernst, for the determination of the melting point of tungsten. This immediately raises the question cited by Langmuir as to whether any luminosity equation derived for a black body is applicable to nonblack bodies. If the nonblack body is gray and if the emissivity is constant with temperature, the equations are directly applicable either for obtaining the apparent blackbody temperature or, after correcting the luminosity by I/ $E$ where $E=$ emissivity coefficient, they are applicable for obtaining the true temperature. The best data upon this question appear in a recent paper by Paterson and Dudding, ${ }^{13}$ who conclude that for all practical purposes many nonblack materials are gray. Their observations upon the melting point of platinum by color match with a black body confirm this conclusion. However, if nonblack materials are not gray to all practical purposes and if metals do possess a temperature coefficient of emissivity in the visible spectrum, it would still be possible to represent the luminosity by an equation of the form of equa-

12 Langmuir, Phys. Rev. (2), 6, p. r38; r9r5.

13 Paterson and Dudding, Proc. Phys. Soc. Lond., 27, p. 230; r9r5. Also Phil. Mag.; rgr5.

$41410^{\circ}-16-10$ 
tion (8), although the constants would differ from those obtained for a black body. Making Langmuir's assumption that the luminosity equation for a black body is directly applicable to tungsten, and that the observed luminosity, 6994 candles $/ \mathrm{cm}^{2}$, can be corrected to correspond with a black body by the factor $\mathrm{I} / E=\mathrm{I} / .5 \mathrm{I}$ and using, instead of the Rasch equation, the equation given under Case III, where $A=2.0 \times 10^{7}$, the melting point of tungsten would be $3602^{\circ}$ absolute. In Langmuir's ${ }^{14}$ paper, page 139 , is given the Rasch equation with the constants determined by Nernst, when the temperature is based on the melting point of gold $=1064^{\circ} \mathrm{C}$. If the equation there cited is supposed to hold at this temperature and this supposition is warranted from Nernst's paper, ${ }^{15}$ the luminosity at the melting point of gold is $.0836 \mathrm{I}$ candles $/ \mathrm{cm}^{2}$. Taking the correct temperature at the melting point of gold as $1063^{\circ} \mathrm{C}$ the constant $A$ of equation (8) becomes $\mathrm{I} .553 \cdot \mathrm{IO}^{7}$. This leads on the basis of Langmuir's data to a value of $\theta=3734^{\circ}$ absolute for the melting point of tungsten. The value obtained by Langmuir is $3528^{\circ}$ absolute. It is more than likely that the value $35^{28}$ is nearer correct than 3734 , but three things must be done before any value obtained by a luminosity method is accepted:(I) The Rasch equation must be discarded; (2) the luminosity of a black body at a known temperature must be determined accurately; and (3) further proof is required that the constants determined in the luminositytemperature relation for a black body apply even approximately for a nonblack body.

Note on the maximum luminous efficiency of a black body: The highest luminous efficiency which a black body can possess occurs at a temperature such that:

$$
\frac{\int_{0}^{\infty} V J d \lambda}{\int_{0}^{\infty} J d \lambda}=\frac{L}{\text { const. } \times \theta^{4}}=\text { maximum. }
$$

Substituting $L$ from equation (8) and evaluating one obtains $\theta_{\max }=6547^{\circ}$ absolute. Another means for obtaining $\theta_{\max }$ is by evaluating the terms on the left of the above equation. The following relation is then obtained:

$$
{ }_{4} \lambda_{\mathrm{L}} \theta_{\max }=c_{2}
$$

If one plots the product $4 \times$ effective wave length $\times$ absolute temperature versus $\theta$, the value of $\theta$ corresponding to ${ }_{4} \lambda_{\mathrm{L}} \theta=c_{2}$ 
is the temperature of the highest luminous efficiency whatever be the luminosity-temperature relation.

\section{SUMMARY}

The relation between luminosity of a black body and temperature has been derived by a new method. The Rasch equation is shown to be unsatisfactory, while the Nutting equation or a slight modification of the Nutting equation holds exceedingly well. The exact meaning of the Crova wave length is defined by equation (2) and is shown to be of the form $\lambda_{\mathrm{L}}=a+b / \theta+c / \theta^{2}$.

The luminosity pyrometer appears advantageous for temperature measurements when calibrated in terms of the Nutting equation or the suggested modification of Nutting's equation. Precise measurements on the luminosity-temperature relation of a black body are greatly to be desired.

WASHINGTON, November I8, I9I 5 . 